\title{
Inspiratory Muscle Training in Rehabilitation of Low Back Pain: A Randomized Controlled Trial
}

\author{
Leila Ahmadnezhad, Ali Yalfani, and Behnam Gholami Borujeni
}

\begin{abstract}
Context: People with chronic low back pain (CLBP) suffer from weaknesses in their core muscle activity and dysfunctional breathing. Inspiratory muscle training (IMT) was recently developed to treat this condition. Objectives: The present study was conducted to investigate the effect of IMT on core muscle activity, pulmonary parameters, and pain intensity in athletes with CLBP. Design: This study was designed as a single-blind, randomized, controlled trial. Setting: Clinical rehabilitation laboratory. Participants: A total of 23 male and 24 female athletes with CLBP were randomly divided into the experimental and control groups. Main Outcome Measures: The experimental group performed IMT for 8 weeks, 7 days per week and twice daily, using POWERbreathe KH1, beginning at 50\% of maximum inspiratory pressure with a progressively increasing training load. The surface electromyography muscle activity of the erector spinae, multifidus, transverse abdominis and rectus abdominis, respiratory function and Visual Analogue Scale score were also measured before and after the intervention in both groups. The repeated-measures analysis of variance and 1-way analysis of covariance were further used to compare the intragroup and intergroup results following the intervention. Results: The findings of the study revealed that multifidus and transverse abdominis activity, as well as respiratory function, increased significantly in the IMT group $(P<.05)$. Moreover, a descending trend was observed in the Visual Analogue Scale score in the experimental group $(P<.05)$. Conclusion: The results showed that IMT can improve respiratory function, increase core muscle activity, and, consequently, reduce pain intensity in athletes with CLBP.
\end{abstract}

Keywords: respiratory muscle exercise, electromyography, pulmonary function, pain intensity, athletes, chronic low back pain

Chronic low back pain (CLBP) is generally accepted as one of the most common musculoskeletal disorders, affecting, on average, $4 \%$ to $33 \%$ of people. CLBP can also affect the quality of life and lead to disability and absenteeism. Approximately $85 \%$ of the cases of low back pain (LBP) are described as nonspecific CLBPs due to the lack of compatibility between their symptoms and radiological findings. ${ }^{1}$ The prevalence rate of CLBP in athletes ranges from $1 \%$ to $40 \% .^{2}$ Back injuries occur in $10 \%$ to $15 \%$ of young athletes and, as such, are a common phenomenon. ${ }^{3}$ CLBP also strikes without a specific pathology or anatomy, and the associated pain usually takes more than 6 months in these patients. The joints, intervertebral discs, tendons, ligaments, and muscles can individually play a major role in the progression of this disease. For example, if transverse abdominis muscle (TVA) activity is delayed, the activity of the global muscles increases in some cases, and vice versa. ${ }^{4}$ The incidence of multifidus muscle (MF) atrophy also results in a reduction in muscle size and an alteration in muscle contraction in those with CLBP. According to a previous study, impaired postural control may be due to reduced coordination in the core muscles, along with increased muscle tension..$^{5}$ Examining and treating the trunk muscles comprise an important part of physiological treatment for patients with CLBP. Patients with CLBP will be more exposed to negative physical, social, psychological, and economic experiences if they do not receive proper treatment; therefore, giving proper rehabilitation to these patients is essential.

Ahmadnezhad, Yalfani, and Gholami Borujeni are with the Department of Sport Injury and Corrective Exercise, Bu-Ali Sina University, Hamadan, Iran. Yalfani is also with the Department of Corrective Exercises and Sport Injury, Faculty of Physical Education and Sport Sciences, Bu-Ali Sina University, Hamedan, Iran. Yalfani (aliyalfani2019@gmail.com) is corresponding author.
For these patients, rehabilitation should be directed toward increasing coordination between the activities of the local and global core muscles. ${ }^{5}$ In general, respiratory movements in the standing position lead to an internal perturbation of body balance, and the resultant disorder can be partially compensated by the hip and the spine movements. Therefore, a decrease in the range of motions and velocity in patients with CLBP causes a reduction in the compensation for respiratory distress, the enhancement of postural sway, and a greater perturbation compared with people without this condition. Some of the outcomes induced by inspiratory exercises in athletes include increased overload tolerance, improved athletic performance, enhanced muscle strength, and elevated airway capacity. ${ }^{6}$ One of these exercises is inspiratory muscle training (IMT), which is believed to improve the strength and endurance of the respiratory muscles. ${ }^{7}$

Inspiratory muscle training is a form of resistance (weight) training that strengthens the muscles of respiration. When these muscles are regularly strengthened for a few weeks, they can manage to work longer. By improving muscle strength before an operation, IMT can reduce breathing complications following orthopedic surgery. ${ }^{7}$

These exercises can be as effective as traditional exercises applied to increase total body performance. ${ }^{8}$ Based on theoretical foundations, long-term inspiratory exercises are likely to affect core muscle activity and improve pulmonary parameters.9,10

As CLBP is a common problem in athletes, clinicians have to be able to identify the most efficacious available treatments for this group. The study hypothesis is that IMT is effective in patients with CLBP. The present research was, therefore, conducted to investigate the effect of 8 weeks of IMT on core muscle activity, pulmonary function, and pain intensity in athletes with CLBP. 


\section{Methods}

\section{Study Design}

The present single-blind, randomized, controlled trial was conducted in accordance with the Declaration of Helsinki 2008 and approved by the ethics committee of Hamedan University of Medical Sciences under the code 1396.933.

\section{Participants}

The study subjects included weightlifting and powerlifting athletes with CLBP who had exercised for at least 3 years 3 times per week and 75 minutes per session, counting the warm-up and cooldown, and who were training in sports clubs across Hamedan city and had visited rehabilitation clinics from June to November 2018. CLBP was defined in this study as pain in the lumbar region (ie, the region between the last ribs and the gluteal sulcus), and patients who reported a pain score of $>3$ based on the Visual Analog Scale (VAS) for pain were included in the study. CLBP was nonspecific, and the source of the pain was not directly identified; however, serious spinal pathology (eg, infection, tumor, arthritis inflammation, etc) was ruled out. The inclusion criteria consisted of having performed powerlifting and weight lifting exercises 3 sessions per week and at least 75 minutes per session over the last 3 years; age range of 18-25 years; LBP persisting for approximately 6 months, but the pain was not severe based on the VAS $(<6)$ and the absence of spine deformity, neck pain, orthopedic or neurological diseases, head or spinal surgeries, rheumatic diseases, and respiratory diseases; and, finally, having a normal curvature of the spinal cord. The subjects did not have acute inflammation of the musculoskeletal system and were not pregnant. The subjects with severe pain, injuries during the intervention, and those using pain relieving medications or receiving physical treatment were excluded from the study. A physical examination was performed by physicians to confirm that the subjects met these eligibility criteria. Informed written consent was also obtained from each participant, and they were asked not to start new additional treatments during the study. All the data were collected at the Clinical Rehabilitation Laboratory.

\section{Sample Size}

The sample size was calculated as 24 per group using G*Power software (G*Power; Franz Faul, University of Kiel, Germany) ${ }^{11}$ and with a $95 \%$ test power, 0.80 effect size, and $\alpha=.05$. The participants were randomly divided into 2 groups (IMT group: $\mathrm{n}=24:$ male $=12$ and female $=12 ;$ control group: $\mathrm{n}=24:$ male $=12$ and female $=12$ ) using the random allocation software by one of the members of the research team as recommended by the CONSORT guidelines. One patient (male) from the IMT group was excluded from the study because he did not return for the follow-up treatment. Figure 1 presents the flow diagram of this study. Table 1 presents the descriptive statistics for age, height, body mass, body mass index, and lumbar arch index.

\section{Outcomes}

The subjects were prohibited from performing intense exercises 2 days before the study. They had performed no physical activity at all 24 hours before the test. They were also forbidden from consuming caffeine before the test and were instead encouraged to sleep for a minimum of 7 hours and eat their last meal 2 hours before the test. The day before the test, the respiratory capacity of the subjects was measured using a JAEGER Spirometer (Oxycon Delta, Germany). Table 2 presents the data on this measurement.

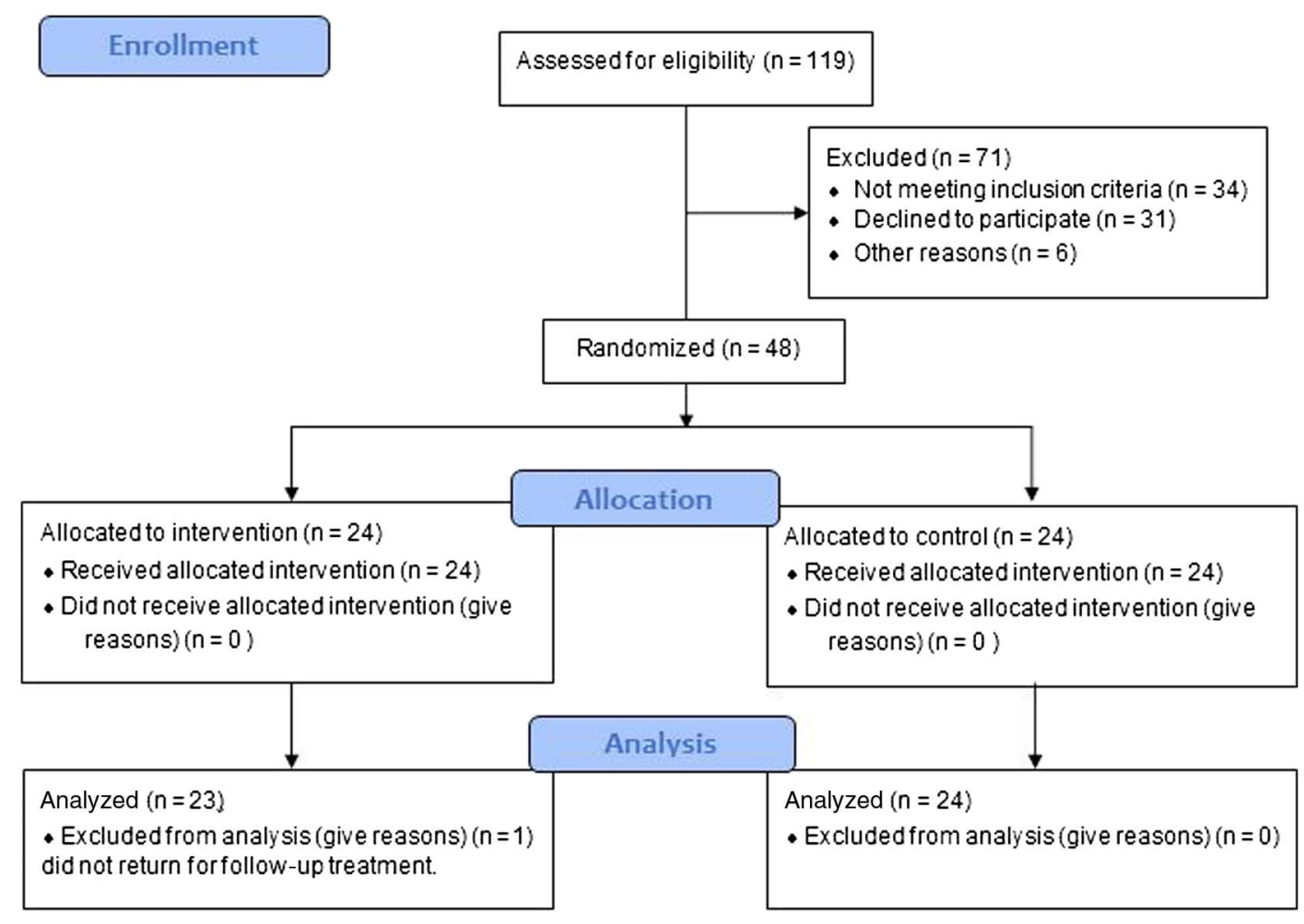

Figure 1 - Clinical trial setup. 
Table 1 Subjects' Characteristics

\begin{tabular}{lcc}
\hline Variable & $\begin{array}{c}\text { Experimental group } \\
\text { Mean (SD) }\end{array}$ & $\begin{array}{c}\text { Control group } \\
\text { Mean (SD) }\end{array}$ \\
\hline Age, y & $21.43(2.15)$ & $22.33(1.41)$ \\
Height, cm & $168.26(10.37)$ & $166.97(8.83)$ \\
Body mass, $\mathrm{kg}$ & $63.23(11.38)$ & $60.13(9.43)$ \\
Body mass index, $\mathrm{kg} \cdot \mathrm{m}^{-2}$ & $22.17(2.88)$ & $21.60(2.62)$ \\
Lumbar arch index, deg & $31.12(4.34)$ & $29.22(5.40)$ \\
\hline
\end{tabular}

The VAS was also used to measure the subjects' pain severity, which ranged from a distance of 0 to $100 \mathrm{~mm}$, and with higher scores indicating a higher intensity of pain. ${ }^{12}$ The lumbar arch was measured with a flexible ruler. ${ }^{13}$ A surface electromyography (sEMG) device (Biomonitor ME6000 T16; Mega Electronics Ltd, Kuopio, Finland) was also used to record the activity of the IMT and control groups 1 day after recording the pulmonary parameters during the overhead squat movements within static and dynamic phases. Before performing the overhead squat, the subjects warmed up for 6 minutes (including 3 min of warm-up with an ergometer with a constant speed and resistance and $3 \mathrm{~min}$ of full-body stretching movements).

The overhead squat is a functional movement screening method used in rehabilitation that requires the strength of the trunk and shoulder muscles and also needs balance to be maintained when moving. Performing this movement requires coordination in the entire kinetic chain. The overhead squat was performed in this study in a way that the subjects opened their legs slightly wider than the shoulder width and straightened them to the front. Their ankles and feet were in a neutral position. Their toes were placed forward with their knees in alignment with their feet (second and third toes). Their arms were placed in alignment with their ears, and their arms were placed symmetrically to the head. They bent their trunk forward, and their arms were positioned exactly in alignment with the trunk. The duration of the static phase was 30 seconds. In this phase, an electrogoniometer, placed at $90^{\circ}$ on the lateral knee, was used to control the angle of the knee. The dynamic test also had descending and ascending phases. The duration of the whole phase was 4 seconds $(2 \mathrm{~s}$ of descending and $2 \mathrm{~s}$ of ascending). The movement speed was also controlled via a metronome at 30 beats per minute. Based on the results of previous studies, those who were unable to perform the overhead squat correctly or had a dynamic and static disorder in the kinetic chain ${ }^{14}$ were excluded from the study (Figure 2).

\section{Procedure}

This study measured muscle activity in 4 muscles, including the erector spinae (ES), MF, TVA, and rectus abdominis (RA). To attach the electrodes, the participants were in standing and relaxed positions, and the anatomical landmarks of each muscle was determined for them before and after the test based on the results of a previous study ${ }^{15}$ Prior to the electrode attachment, the skin was cleaned with alcohol at the placement site, and its hair was removed through a thin sandpaper by shaving to reduce the skin resistance to EMG signals. Before the electrodes were attached, the subjects respired deeply and held to attach the electrodes. ${ }^{16}$ The surface electrodes were placed at standard points according to the existing guidelines, oriented parallel to the muscle fibers to ensure optimal signal recording. A surface $\mathrm{Ag}-\mathrm{AgCl}$ electrode (ECG Electrodes; Skintact, Innsbruck, Austria) was then mounted using sEMG for the noninvasive assessment of the muscles by the SENIAM method on the dominant side of the muscle ventricle, such that the distance between the centers of the 2 electrodes was $2 \mathrm{~cm} .{ }^{17}$ Electrode placement was as follows: about $3 \mathrm{~cm}$ lateral to the umbilicus in a vertical direction for the RA; $2 \mathrm{~cm}$ inferior and medial to the anterior superior iliac spine within the inguinal ligament for the TVA; at the level of L5 spinous process, along (and aligned with) a line from the posterior-superior spina iliaca to the interspace between L1 and L2 (about 2-3 cm from the midline) for the MF; and at the levels of the T7 and L4 vertebrae, approximately 3 to $4 \mathrm{~cm}$ from the midline of the back for the ES..$^{15}$ The reference electrode was also placed in the anterior superior iliac spine of the dominant side.

\section{EMG Data Analysis}

The EMG data were analyzed in MATLAB software (MathWorks, Natick, MA). This study set the sampling rate of the signals collected through the electrodes to $2000 \mathrm{~Hz}$, and the signal-tonoise ratio was reported as $90 \mathrm{Db}$. For the EMG analysis, to remove the effects of unwanted signals, this study set the band pass filter to

Table 2 The Result of Respiratory Function and Pain Intensity Before and After IMT

\begin{tabular}{|c|c|c|c|c|c|c|c|c|}
\hline Variables & Group & $\begin{array}{c}\text { BT } \\
\text { Mean (SD) }\end{array}$ & $\begin{array}{c}\text { AT } \\
\text { Mean (SD) }\end{array}$ & $F$ (WG) & $P$ (WG) & $F(B G)$ & $P$ (BG) & $\begin{array}{l}\text { Effect } \\
\text { size, } d\end{array}$ \\
\hline \multirow[t]{2}{*}{$\mathrm{VC}$} & Training & $3.91(0.15)$ & $4.28(0.27)$ & 81.69 & $<.001^{*}$ & 38.37 & $<.001 *$ & 0.636 \\
\hline & Control & $4.02(0.11)$ & $4.07(0.14)$ & 0.13 & .73 & & & \\
\hline \multirow[t]{2}{*}{$\mathrm{FVC}$} & Training & $4.18(0.20)$ & $4.43(0.24)$ & 62.36 & $<.001^{*}$ & 22.79 & $<.001 *$ & 0.509 \\
\hline & Control & $4.22(0.29)$ & $4.25(0.28)$ & 2.09 & .19 & & & \\
\hline \multirow[t]{2}{*}{$\mathrm{FEV}_{1}$} & Training & $4.04(0.09)$ & 4. $17(0.41)$ & 32.02 & $<.001^{*}$ & 19.263 & $<.001 *$ & 0.467 \\
\hline & Control & $4.07(0.09)$ & $4.08(0.06)$ & 0.99 & .76 & & & \\
\hline \multirow[t]{2}{*}{ FEV/VC } & Training & $76.68(2.14)$ & $78.76(1.78)$ & 8.58 & $.01 *$ & 5.395 & $.03 *$ & 0.197 \\
\hline & Control & $76.95(2.55)$ & $76.96(2.45)$ & 0 & .99 & & & \\
\hline \multirow[t]{2}{*}{ Pain, cm } & Training & $5.99(0.27)$ & $5.26(0.39)$ & 37.6 & $<.001 *$ & 5.416 & $.03 *$ & 0.198 \\
\hline & Control & $5.52(0.33)$ & $5.72(0.24)$ & 1.8 & .22 & & & \\
\hline
\end{tabular}

Abbreviations: AT, after training; BG, between groups; BT, before training; FEV, forced expiratory volume; $\mathrm{FEV}_{1}$, forced expiratory volume in 1 second; FVC, forced vital capacity; IMT, inspiratory muscle training; VC, vital capacity; WG, within group.

$* P<.05$. 


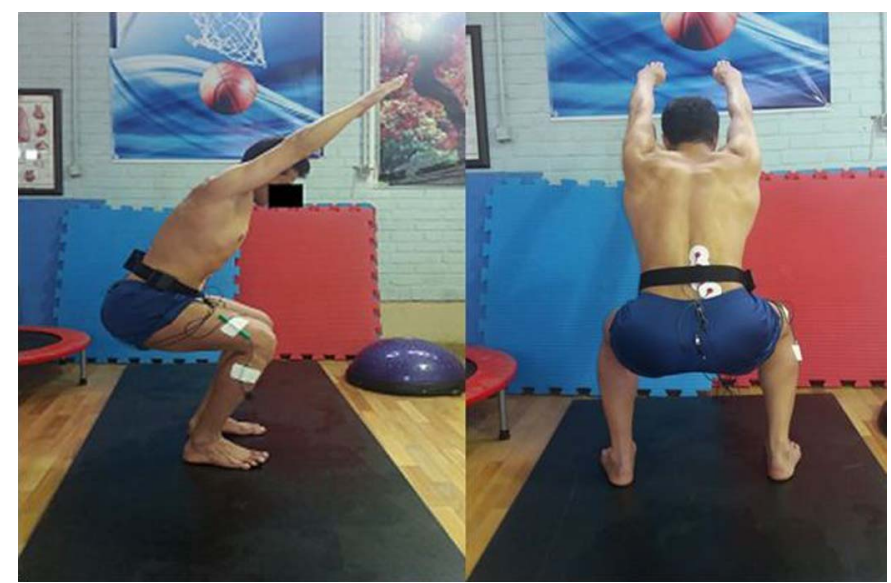

Figure 2 - Overhead squats.

10 to $500 \mathrm{~Hz}$. As some displacement or error in the attachment of the electrodes in the pretest and posttest is inevitable, to normalize the action potential of each muscle, the maximal voluntary isometric contraction (MVIC) was used as well. The maximum isometric contraction was measured against manual resistance for 5 seconds, and after excluding 1 second from the first and last parts, the average EMG signal for 3 seconds was used as the MVIC (in percentage). ${ }^{18}$ The root mean square values of the 3 trials were averaged and then normalized by MVIC. ${ }^{19}$

The MVIC tests for the selected muscles were as follows:

For the RA, the participants lied down with their hips and knees flexed to $90^{\circ}$ and their trunk maximally flexed (ie, curled up) against a bilateral shoulder resistance manually provided by the experimenter by pushing the trunk into extension. For the TVA, the participants exerted additional resisted trunk rotation to the right and left. For the ES, the resisted trunk extension was performed with the subject lying prone on a treatment table. For the MF, the resisted trunk extension was performed with the subject lying prone on a treatment table. ${ }^{15}$

The cocontraction of the local and global muscles was calculated using the following formula:

Cocontraction $=\mathrm{EMG}_{\mathrm{s}} / \mathrm{EMG}_{\mathrm{L}}\left(\mathrm{EMG}_{\mathrm{s}}+\mathrm{EMG}_{\mathrm{L}}\right)$, where $\mathrm{EMG}_{\mathrm{s}}$ is the normalized magnitude of the EMG signal for the less active muscle, and $\mathrm{EMG}_{\mathrm{L}}$ is the normalized magnitude of the EMG signal for the more highly active muscle.

\section{Intervention}

POWERbreathe KH1 (HaB International Ltd, Southam, United Kingdom) was used as a handheld device for testing and monitoring exercises performed in individuals in need of a comprehensive program for inspiratory muscle exercises ${ }^{20}$ This device is ideal for people who want to see their own recovery during training. It also strengthens the respiratory muscles by performing resistance breathing exercises and measuring the maximum respiratory pressure.

The experimental group in this study performed IMT with this device. The intervention instructions were as follows. First, each subject experimented with POWERbreathe and was introduced to the training protocol with POWERbreathe by a therapist in an instructional session, and then practiced with the device. In the first session, the patients were asked to get into a sitting position and perform IMT to $50 \%$ of their maximum inspiratory pressure $\left(\mathrm{Pi}_{\max }\right)$, at most, using the manual setup option. The overall training intensity was then gradually increased. The training pressure was also increased by $5 \%$ per week to a maximum of $90 \% \mathrm{Pi}_{\max }$. The respiratory effort scores reported by patients after training sessions should ideally be at the range of 4 to 6 out of 10 on the modified Borg scale. ${ }^{21}$ Instructions and recommendations given during the sessions were also standardized by the therapist's verbal feedback. The experimental group performed IMT for 8 weeks, 7 twice daily sessions per week, each consisting of 30 breaths with a breathing frequency of 15 per minute. ${ }^{22}$ During this period, the subjects did not perform any other CLBP treatments, except for the IMT protocol described in this study, and continued their regular sports practices. The control group did not receive any exercise programs, except for weightlifting and powerlifting training (Figure 1).

All the procedures were performed in the pretest and posttest by the same examiner for both groups, and the examiner was blinded to them.

\section{Statistical Analysis}

The data collected were analyzed in SPSS-20 (SPSS Inc, Chicago, IL), and the significance level was set at $\alpha=.05$ using descriptive statistics (mean [SD]). The Shapiro-Wilk test was also used to determine the normal distribution of the data.

The repeated-measures analysis of variance was used to compare the selected muscle activity and respiratory function, and the intragroup VAS score was measured before and after IMT.

The effect of IMT was also calculated by comparing the differences in the outcomes measured using the 1-way analysis of covariance over the 8-week training program, and the Bonferroni post hoc test was used to analyze the data (pretest scores were used as the covariate). The odds ratios and corresponding 95\% confidence intervals were further estimated to assess the differences between the study groups.

\section{Results}

\section{Muscle Activity}

The EMG activity findings from the intragroup changes in the static test revealed that the activity of the RA $(P=.01)$ and ES $(P<.001)$, and the cocontraction of these global muscles $(P=.01)$ decreased significantly in the experimental group. TVA $(P<.001)$, MF $(P<$ $.001)$, and the cocontraction rate of these local muscles $(P<.001)$ had also increased in a significant manner in the experimental group. Moreover, there was a significant difference in the activity of ES $(P=.01, d=0.275)$, MF $(P<.001, d=0.502)$, RA $(P=.01$, $d=0.303)$, TVA $(P<.001, d=0.687)$, and the cocontraction rate of the local muscles $(P<.001, d=0.455)$ and global muscles $(P<.001, d=0.228)$ between the experimental and control groups (Table 3).

The results of the selected muscle activity in the descending phase of the dynamic test also indicated a significant increase in the activity of MF $(P=.002)$ and TVA $(P<.001)$ and the cocontraction of the local muscles $(P<.001)$, along with a significant reduction in the activity of ES $(P=.001)$ and RA $(P<.001)$ and the cocontraction of the global muscles $(P=.001)$ in the experimental group. The between-group changes also showed a significant difference in the activity of TVA $(P=.01, d=0.312), \operatorname{MF}(P=.001, d=0.391)$, and RA $(P<.001, d=473)$, and the cocontraction of the local $(P=.02$, $d=0.217)$ and global $(P=.01, d=0.269)$ muscles between the 
Table 3 The Result of Muscle Activity Before and After IMT in Static Overhead Squat

\begin{tabular}{|c|c|c|c|c|c|c|c|c|}
\hline Muscles & Group & $\begin{array}{c}\text { BT } \\
\text { Mean (SD) }\end{array}$ & $\begin{array}{c}\text { AT } \\
\text { Mean (SD) }\end{array}$ & $F(W G)$ & $P$ (WG) & $F(B G)$ & $P$ (BG) & $\begin{array}{l}\text { Effect } \\
\text { size, } d\end{array}$ \\
\hline \multirow[t]{2}{*}{ ES } & Training & $28.39(13.2)$ & $26.26(12.41)$ & 24.24 & $<.001 *$ & 8.36 & $.01 *$ & 0.275 \\
\hline & Control & $31.13(10.13)$ & $30.51(10.23)$ & 4.55 & .07 & & & \\
\hline \multirow[t]{2}{*}{ MF } & Training & $23.32(11.54)$ & $26.30(10.33)$ & 20.64 & $<.001^{*}$ & 22.21 & $<.001^{*}$ & 0.502 \\
\hline & Control & $25.20(6.69)$ & $23.70(6.01)$ & 4.33 & .07 & & & \\
\hline \multirow[t]{2}{*}{ RA } & Training & $16.05(16.35)$ & $13.31(13.08)$ & 6.95 & $.01 *$ & 9.57 & $.01 *$ & 0.303 \\
\hline & Control & $19.14(18.46)$ & $19.35(18.24)$ & 0.55 & .48 & & & \\
\hline \multirow[t]{2}{*}{ TVA } & Training & $9.23(7.37)$ & 13.66 (6.99) & 114.1 & $<.001 *$ & 48.39 & $<.001 *$ & 0.687 \\
\hline & Control & $11.69(6.74)$ & $11.85(6.15)$ & 0.189 & .68 & & & \\
\hline \multirow[t]{2}{*}{ Co-global } & Training & $16.81(8.96)$ & $13.59(7.02)$ & 9.34 & $.01 *$ & 6.49 & $<.001 *$ & 0.228 \\
\hline & Control & $27.69(27.87)$ & $27.59(27.52)$ & 0.045 & .84 & & & \\
\hline \multirow[t]{2}{*}{ Co-local } & Training & $12.38(9.58)$ & $19.67(9.01)$ & 57.87 & $<.001 *$ & 18.39 & $<.001^{*}$ & 0.455 \\
\hline & Control & $18.53(13.42)$ & $19.12(12.97)$ & 0.557 & .48 & & & \\
\hline
\end{tabular}

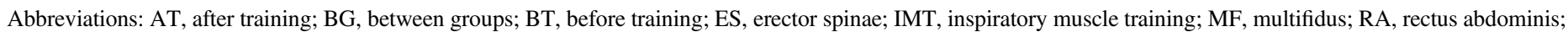
TVA, transverse abdominis; WG, within group.

$* P<.05$.

experimental and control groups. The results from the ascending phase showed that intragroup changes in the activity rate of ES $(P<.001)$ and RA $(P<.001)$ and the cocontraction of the global muscles decreased significantly $(P<.001)$, and the activity of MF $(P=.01)$ and TVA $(P=.001)$ and the cocontraction rate of these local muscles $(P=.003)$ increased significantly in the experimental group. The 1-way analysis of covariance showed a significant difference in all the factors, that is, MF $(P=.002, d=0.356)$, TVA $(P=.01, d=0.274)$, the cocontraction of the local muscles $(P=.02$, $d=0.207)$, ES $(P=.003, d=0.334), \mathrm{RA}(P<.001, d=0.620)$, and the cocontraction of the global muscles $(P=.01, d=0.481)$ between the 2 study groups (Table 4).

\section{Respiratory Function and VAS Score}

Respiratory function increased significantly in the experimental group after 8 weeks of IMT (vital capacity [VC], $P<.001$; forced vital capacity, $P<.001$; forced expiratory volume in $1 \mathrm{~s}$, FEV $P<.001$; and forced expiratory volume [FEV]/VC, $P=.01$ ), but these results were not significant in the control group. In addition, pain intensity decreased significantly in the experimental group $(P<.001)$. The 1-way analysis of covariance also demonstrated a significant increase in respiratory function (VC $[P<.001$, $d=0.636]$, forced vital capacity $[P<.001, d=0.509], \mathrm{FEV}_{1}$ $[P<.001, d=0.467]$, and FEV/VC $[P=.03, d=0.197])$, and a significant reduction in pain intensity $(P=.03, d=0.198)$ as a result of these exercises (Table 2).

\section{Discussion}

The primary outcome of IMT was the increase in the activity of the core muscles in both static and dynamic overhead squat tests. The activity of the TVA muscle in athletes with CLBP increased significantly in the experimental group. The important point is that the results between the 2 study groups were statistically and clinically (with a large effect size in the static test $[d=0.687]$ and descending $[d=0.312]$ and ascending phase $[d=0.274]$ of the dynamic test) significant. The findings also revealed that the patients with CLBP faced delays in their local muscle contraction and activity. ${ }^{23}$ The TVA muscle is located deep in the abdomen and is known as a girdle or corset muscle because it stabilizes the back and can lead to intraabdominal pressure due to connection to the thoracolumbar fascia. Of all the core muscles, the TVA muscle has the widest and closest connection to the thoracolumbar fascia and is also essential for spinal stability. Previous studies on different respiratory exercises, including diaphragmatic and yoga breathing exercises, have further highlighted the major role of these exercises in improving the stability of the intervertebral joints and increasing motion control in patients with LBP. ${ }^{24,25}$ For example, Hodges et $\mathrm{a}^{25}$ reported that the respiratory muscles are an important factor in spinal stability. Particularly, if the activity of the respiratory and abdominal muscles is unknown, spinal stability can decrease along with intraabdominal pressure reduction. Urquhart et $\mathrm{a}^{26}$ also concluded that stabilizer exercises alone cannot increase the activity of the local muscles and have to be accompanied by respiratory exercises. The results obtained by Marshall et $\mathrm{al}^{27}$ were also consistent with the results of the present study, as they underlined that the activity of the RA, TVA, external oblique, and ES muscles increases during respiratory exercises in patients with CLBP and a significant difference exists in TVA activity. The use of SEMG also plays an important role in the determination of trunk muscle activity in patients with CLBP. ${ }^{28}$ The surface electrodes placed in the muscle ventricle can accurately reflect the total activity of the muscle. To explain the increased activity of the local muscle after 8 weeks of IMT, it can be argued that the increase in the activity of the local muscle reflected in the sEMG is due to the changes in the motor units from the random mode before performing IMT to the synchronized mode after 8 weeks of IMT. Once the motor units are in the synchronized mode, more components are engaged in muscle activity, which increases the amount of activity amplitude observed in EMG. The increased local muscle activity can also be due to neural factors, as the nerves of these muscles, such as the thoracoabdominal nerve, are stimulated after IMT due to the overload in these muscles. Following IMT and muscle activation and the activity of the motor units, the simultaneous strengthening of neuromuscular system activity can lead to a rise in the activity of the local muscles. ${ }^{29}$ In the present study, the cocontraction rate increased in the static test $(d=0.455)$ and descending $(d=0.217)$ and ascending phase $(d=0.207)$ of the dynamic test as one of the 
Table 4 The Result of Muscle Activity Before and After IMT in the Descending and Ascending Phase of the Dynamic Test of Overhead Squat

\begin{tabular}{|c|c|c|c|c|c|c|c|c|}
\hline Muscles & Group & $\begin{array}{c}\text { BT } \\
\text { Mean (SD) }\end{array}$ & $\begin{array}{c}\text { AT } \\
\text { Mean (SD) }\end{array}$ & $F$ (WG) & $P$ (WG) & $F(B G)$ & $P$ (BG) & $\begin{array}{l}\text { Effect } \\
\text { size, } d\end{array}$ \\
\hline \multicolumn{9}{|c|}{ Descending phase } \\
\hline \multirow[t]{2}{*}{ ES } & Training & $30.89(6.75)$ & $26.31(6.82)$ & 15.52 & $.001 *$ & 2.68 & .12 & 0.508 \\
\hline & Control & $33.36(7.87)$ & $32.20(9.71)$ & 0.21 & .65 & & & \\
\hline \multirow[t]{2}{*}{$\mathrm{MF}$} & Training & $28.32(7.54)$ & $34.39(7.32)$ & 14.76 & $.002 *$ & 14.14 & $.001 *$ & 0.391 \\
\hline & Control & $27.42(3.32)$ & $25.08(5.94)$ & 2.13 & .18 & & & \\
\hline \multirow[t]{2}{*}{ RA } & Training & $24.17(5.38)$ & $15.43(5.47)$ & 21.2 & $<.001 *$ & 19.74 & $<.001 *$ & 0.473 \\
\hline & Control & $28.03(3.59)$ & $28.56(7.86)$ & 0.34 & .86 & & & \\
\hline \multirow[t]{2}{*}{ TVA } & Training & $10.48(4.60)$ & $17.35(4.41)$ & 35.26 & $<.001^{*}$ & 9.996 & $.01 *$ & 0.312 \\
\hline & Control & $10.58(2.63)$ & $11.61(4.62)$ & 0.28 & .61 & & & \\
\hline \multirow[t]{2}{*}{ Co-global } & Training & $41.01(9.96)$ & $25.69(11.14)$ & 19.334 & $.001 *$ & 8.078 & $.01 *$ & 0.269 \\
\hline & Control & $47.88(6.84)$ & 46.30 (18.49) & 0.094 & .77 & & & \\
\hline \multirow[t]{2}{*}{ Co-local } & Training & $15.70(9.57)$ & $26.50(8.28)$ & 27.497 & $<.001 *$ & 6.079 & $.02 *$ & 0.217 \\
\hline & Control & $14.80(4.40)$ & $17.93(8.88)$ & 0.787 & .40 & & & \\
\hline \multicolumn{9}{|c|}{ Ascending phase } \\
\hline \multirow[t]{2}{*}{ ES } & Training & $32.21(6.94)$ & $23.81(3.55)$ & 47.64 & $<.001 *$ & 11.00 & $.003^{*}$ & 0.334 \\
\hline & Control & $35.58(6.13)$ & $33.31(9.28)$ & 0.471 & .51 & & & \\
\hline \multirow[t]{2}{*}{$\mathrm{MF}$} & Training & $29.57(6.49)$ & $35.64(7.28)$ & 9.65 & $.01 *$ & 12.15 & $.002 *$ & 0.356 \\
\hline & Control & $27.42(3.32)$ & $25.08(5.94)$ & 2.13 & .18 & & & \\
\hline \multirow[t]{2}{*}{ RA } & Training & $27.30(3.95)$ & 14. $80(5.20)$ & 44.33 & $<.001 *$ & 35.88 & $<.001^{*}$ & 0.62 \\
\hline & Control & $32.48(4.98)$ & $31.89(6.33)$ & 0.09 & .76 & & & \\
\hline \multirow[t]{2}{*}{ TVA } & Training & $12.98(4.55)$ & $19.85(5.03)$ & 15.15 & $.001 *$ & 8.316 & $.01 *$ & 0.274 \\
\hline & Control & $15.03(3.21)$ & $13.84(3.75)$ & 0.498 & .50 & & & \\
\hline \multirow[t]{2}{*}{ Co-global } & Training & $47.17(8.68)$ & $25.23(11.45)$ & 31.405 & $<.001 *$ & 20.378 & $.01 *$ & 0.481 \\
\hline & Control & $54.35(7.46)$ & $53.93(18.91)$ & 0.004 & .95 & & & \\
\hline \multirow[t]{2}{*}{ Co-local } & Training & $20.03(9.33)$ & $32.01(11.10)$ & 12.461 & $.003 *$ & 5.744 & $.02 *$ & 0.207 \\
\hline & Control & $23.93(7.39)$ & $21.98(7.22)$ & 0.288 & .61 & & & \\
\hline
\end{tabular}

Abbreviations: AT, after training; BG, between groups; BT, before training; ES, erector spinae; IMT, inspiratory muscle training; MF, multifidus; RA, rectus abdominis; TVA, transverse abdominis; WG, within group.

$* P<.05$.

positive effects of these exercises, leading to increased lumbar stability. ${ }^{27}$ The increase in local muscle activity and the cocontraction of these muscles can both be taken as factors contributing to the reduction of pain in patients with CLBP $(d=0.198)$, as observed in this study. Another result of this study was the increase in respiratory parameters in athletes with CLBP after 8 weeks of IMT, with a large effect size (VC: $d=0.636$, forced vital capacity: $\left.d=0.509, \mathrm{FEV}_{1}: d=0.467, \mathrm{FEV} / \mathrm{VC}: d=0.197\right)$. In the respiratory system, ventilation is the process in which the lung sends air into the blood through the respiratory muscles. ${ }^{30}$ When a patient has neuromuscular weakness, the respiratory muscles become unable to reach the maximum level of airflow and lung pressure. ${ }^{31}$ Rathinaraj et $\mathrm{al}^{32}$ reported that patients with CLBP have a reduced FEV1 due to the weaknesses in their back flexor and extensor muscles, which lead to increased pain and decreased functional movement. The abdominal muscles are responsible for approximately $20 \%$ of respiratory functions, resulting in changes in the lung function. ${ }^{33}$ TVA muscles are mainly involved in lumbar spine stability. ${ }^{34}$ The TVA muscles, along with MF, provide spinal stability during inspiration. While breathing, the TVA muscle is more active than the other abdominal muscles. Similarly, the TVA muscle is more active than the other respiratory muscles in expiration, such as the RA and internal and external oblique muscles. There is also an obvious weakness in the core muscles of people suffering from CLBP. The weakness of the trunk muscle also leads to impaired breathing and increased pain in this group of patients. ${ }^{35}$ Muscular imbalance and spinal instability also occur due to the weakness of the core muscles, especially the TVA and MF, which have a direct correlation with respiratory function. ${ }^{36,37}$

An increase in respiratory function in patients with CLBP is, therefore, likely to occur due to the increased local muscle activity following IMT.

\section{Limitations}

This study had several limitations. First, the sample was small, and all the subjects were young (age range of 18-25 y). Second, all the subjects were athletes, which means that the results cannot represent the conditions of the entire population. Another limitation was that degenerative conditions were not considered in this study. The fourth limitation was using sEMG for recording muscle activity, as this device could not record all the local muscles, and more muscles needed to be evaluated with other methods. These limitations should be addressed in future studies, and a long-term follow-up 
is also recommended to ensure that the given exercise is effective for patients with CLBP and to strengthen the validity and credibility of the findings.

\section{Conclusion}

According to the results obtained from the present study, IMT can increase the activity of the local trunk muscles and enhance respiratory function in athletes with CLBP, thereby reducing the pain intensity in these individuals and enhancing their functional activities. As these exercises are easy and accessible, sports therapists, rehabilitation care practitioners, physicians, and trainers are recommended to use them to improve respiratory function, increase core stability, and reduce pain intensity in people with LBP.

\section{Acknowledgments}

The authors would like to express their gratitude to all the athletes who participated in this research. The authors declare that they have no personal or professional conflicts of interest regarding any aspect of this study. This study was approved by the ethics committee of Hamedan University of Medical Sciences with the code of IR.UMSHA.REC.1396.933.

\section{References}

1. Psycharakis SG, Coleman SG, Linton L, Kaliarntas K, Valentin S. Muscle activity during aquatic and land exercises in people with and without low back pain. Phys Ther. 2019;99(3):297-310. PubMed ID: 30690522 doi:10.1093/ptj/pzy 150

2. Bono CM. Low-back pain in athletes. J Bone Joint Surg Am. 2004; 86(2):382-396. PubMed ID: 14960688 doi:10.2106/00004623200402000-00027

3. d'Hemecourt PA, Gerbino PG II, Micheli LJ . Back injuries in the young athlete. Clin Sports Med. 2000;19(4):663-679. doi:10.1016/ S0278-5919(05)70231-3

4. O'sullivan K, O'Keeffe M, Forster BB, Qamar SR, van der Westhuizen A, O'sullivan PB. Managing low back pain in active adolescents. Best Pract Res Clin Rheumatol. 2019;33(1):102-121. doi:10.1016/j.berh.2019.02.005

5. Djordjevic O, Konstantinovic L, Miljkovic N, Bijelic G. Relationship between electromyographic signal amplitude and thickness change of the trunk muscles in patients with and without low back pain. Clin J Pain. 2015;31(10):893-902. PubMed ID: 25380224 doi:10.1097/ AJP.0000000000000179

6. Hamaoui A, Do MC, Poupard L, Bouisset S. Does respiration perturb body balance more in chronic low back pain subjects than in healthy subjects? Clin Biomech. 2002;17(7):548-550. doi:10.1016/S02680033(02)00042-6

7. Berlowitz DJ, Tamplin J. Respiratory muscle training for cervical spinal cord injury. Cochrane Database of Syst Rev. 2013;(7): CD008507.

8. Rakobowchuk M, Tanguay S, Burgomaster KA, Howarth KR, Gibala MJ, MacDonald MJ. Sprint interval and traditional endurance training induce similar improvements in peripheral arterial stiffness and flowmediated dilation in healthy humans. Am J Physiol Regul Integr Comp Physiol. 2008;295(1):R236-R242. PubMed ID: 18434437 doi:10.1152/ajpregu.00069.2008

9. Vasconcelos T, Hall A, Viana R. The influence of inspiratory muscle training on lung function in female basketball players - a randomized controlled trial. Porto Biomed J. 2017;2(3):86-89. doi:10.1016/j.pbj. 2016.12.003

10. Oh D, Kim G, Lee W, Shin MM. Effects of inspiratory muscle training on balance ability and abdominal muscle thickness in chronic stroke patients. J Phys Ther Sci. 2016;28(1):107-111. PubMed ID: 26957739 doi:10.1589/jpts.28.107

11. Faul F, Erdfelder E, Lang AG, Buchner A. G*Power 3: a flexible statistical power analysis program for the social, behavioral, and biomedical sciences. Behav Res Methods. 2007;39(2):175-191. PubMed ID: 17695343 doi:10.3758/BF03193146

12. Boonstra AM, Preuper HR, Balk GA, Stewart RE. Cut-off points for mild, moderate, and severe pain on the visual analogue scale for pain in patients with chronic musculoskeletal pain. Pain. 2014; 155(12):2545-2550. PubMed ID: 31759327 doi:10.1016/j.pain. 2014.09.014

13. de Oliveira TS, Candotti CT, La Torre M, et al. Validity and reproducibility of the measurements obtained using the flexicurve instrument to evaluate the angles of thoracic and lumbar curvatures of the spine in the sagittal plane. Rehabil Res Pract. 2012;2012:186156. PubMed ID: 22619723

14. Glass SC, Albert RW. Compensatory muscle activation during unstable overhead squat using a water-filled training tube. $J$ Strength Cond Res. 2018;32(5):1230-1237. PubMed ID: 28557850 doi:10. 1519/JSC.0000000000002000

15. Ng JK, Richardson CA, Parnianpour M, Kippers V. EMG activity of trunk muscles and torque output during isometric axial rotation exertion: a comparison between back pain patients and matched controls. J Orthop Res. 2002;20(1):112-121. PubMed ID: 11855379 doi:10. 1016/S0736-0266(01)00067-5

16. Fontes AE, de Andrade L, Feitosa LA, et al. Acute effects of incremental inspiratory loads on compartmental chest wall volume and predominant activity frequency of inspiratory muscle. J Electromyogr Kinesiol. 2013;23(6):1269-1277. doi:10.1016/j.jelekin.2013.07.014

17. Mok NW, Yeung EW, Cho JC, Hui SC, Liu KC, Pang CH. Core muscle activity during suspension exercises. J Sci Med Sport. 2015; 18(2):189-194. PubMed ID: 24556020 doi:10.1016/j.jsams.2014. 01.002

18. Hislop H. Daniels and Worthingham's Muscle Testing: Techniques of Manual Examination and Performance Testing. 9th ed. Riverport, MD: Elsevier; 2013.

19. Vezina MJ, Hubley-Kozey CL. Muscle activation in therapeutic exercises to improve trunk stability. Arch Phys Med Rehabil. 2000;81(10):1370-1379. PubMed ID: 11030503 doi:10.1053/apmr. 2000.16349

20. McDonald T, Stiller K. Inspiratory muscle training is feasible and safe for patients with acute spinal cord injury. J Spinal Cord Med. 2019; 42(2):220-227. PubMed ID: 29400990 doi:10.1080/10790268.2018. 1432307

21. Charususin N, Gosselink R, Decramer M, et al. Inspiratory muscle training protocol for patients with chronic obstructive pulmonary disease (IMTCO study): a multicentre randomised controlled trial. BMJ Open. 2013;3(8):e003101. PubMed ID: 23921069 doi:10.1136/ bmjopen-2013-003101

22. Janssens L, McConnell AK, Pijnenburg M, et al. Inspiratory muscle training affects proprioceptive use and low back pain. Med Sci Sports Exerc. 2015;47(1):12-19. PubMed ID: 24870567 doi:10.1249/ MSS.0000000000000385

23. Meziat Filho N, Santos S, Rocha RM. Long-term effects of a stabilization exercise therapy for chronic low back pain. Man Ther. 2009;14(4):444-447. PubMed ID: 19026587 doi:10.1016/j.math. 2008.10.002 
24. Macedo LG, Latimer J, Maher CG, et al. Effect of motor control exercises versus graded activity in patients with chronic nonspecific low back pain: a randomized controlled trial. Phys Ther. 2012; 92(3):363-377. PubMed ID: 22135712 doi:10.2522/ptj.20110290

25. Hodges PW, Eriksson AM, Shirley D, Gandevia SC. Intra-abdominal pressure increases stiffness of the lumbar spine. J Biomech. 2005; 38(9):1873-1880. PubMed ID: 16023475 doi:10.1016/j.jbiomech. 2004.08.016

26. Urquhart DM, Barker PJ, Hodges PW, Story IH, Briggs CA. Regional morphology of the transversus abdominis and obliquus internus and externus abdominis muscles. Clin Biomech. 2005;20(3):233-241. doi:10.1016/j.clinbiomech.2004.11.007

27. Marshall PW, Desai I, Robbins DW. Core stability exercises in individuals with and without chronic nonspecific low back pain. J Strength Cond Res. 2011;25(12):3404-3411. PubMed ID: 22080309 doi:10.1519/JSC.0b013e318215fc49

28. Danneels L, Coorevits P, Cools A, et al. Differences in electromyographic activity in the multifidus muscle and the iliocostalis lumborum between healthy subjects and patients with sub-acute and chronic low back pain. Eur Spine J. 2002;11(1):13-19. PubMed ID: 11931058 doi:10.1007/s005860100314

29. Chiu LZ, Fry AC, Schilling BK, Johnson EJ, Weiss LW. Neuromuscular fatigue and potentiation following two successive high intensity resistance exercise sessions. Eur J Appl Physiol. 2004;92(4-5):38592. PubMed ID: 15185085 doi:10.1007/s00421-004-1144-z

30. Pryor JA, Prasad AS. Physiotherapy for Respiratory and Cardiac Problems: Adults and Paediatrics. Edinburgh, UK: Elsevier Health Sciences; 2008.
31. Perrin C, Unterborn JN, Ambrosio CD, Hill NS. Pulmonary complications of chronic neuromuscular diseases and their management. Muscle Nerve. 2004;29(1):5-27. PubMed ID: 14694494 doi:10.1002/ mus. 10487

32. Rathinaraj LA, Irani A, Sharma SK, Ng B, Sreeja MT. Forced Expiratory Volume in the first second $\left[\mathrm{FEV}_{1}\right]$ in patients with chronic low back pain. J Res Med Den Sci. 2017;5(1):27-32. doi:10.5455/ jrmds. 2017516

33. Almeida VP, Guimarães FS, Moço VJ, Menezes SL, Mafort TT, Lopes AJ. Correlation between pulmonary function, posture, and body composition in patients with asthma. Rev Port Pneumol (English Edition). 2013;19(5):204-210. doi:10.1016/j.rppnen.2013.03.005

34. Kim E, Lee $\mathrm{H}$. The effects of deep abdominal muscle strengthening exercises on respiratory function and lumbar stability. J Phys Ther Sci. 2013;25(6):663-665. PubMed ID: 24259823 doi:10.1589/jpts. 25.663

35. Teixeira-Salmela LF, Parreira VF, et al. Respiratory pressures and thoracoabdominal motion in community-dwelling chronic stroke survivors. Arch Phys Med Rehab. 2005;86(10):1974-1978. doi:10. 1016/j.apmr.2005.03.035

36. Comerford MJ, Mottram SL. Movement and stability dysfunctioncontemporary developments. Man Ther. 2001;6(1):15-26. PubMed ID: 11243905 doi:10.1054/math.2000.0388

37. Key J, Clift A, Condie F, Harley C. A model of movement dysfunction provides a classification system guiding diagnosis and therapeutic care in spinal pain and related musculoskeletal syndromes: a paradigm shift—part 1. J Bodyw Mov Ther. 2008;12(1):7-21. PubMed ID: 19083651 doi:10.1016/j.jbmt.2007.04.005 